$23-30$

\title{
大气边界层对日本琵琶湖物理过程的影响”
}

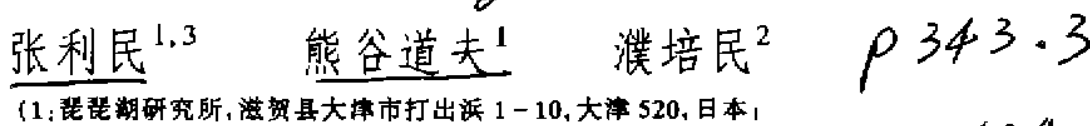 \\ 2: 中国科学完南京地理与湖泊研究所, 南京 210008 ; 3: 江苏省环境保护同, 南京 210013) 0404
}

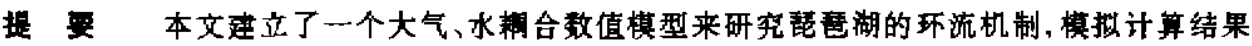
表明：1 在湖面上存在一个正的风漏度场以及白天的正散度场、晩上的负散度场、在温度分层的季

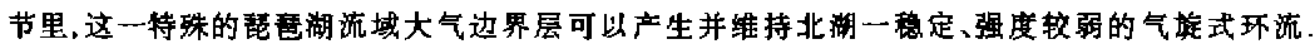

2) 当考否大气边界层的不均为风场的影响时, 湖中形成的环流比均匀风场驱动形成的环流更加稳 定且维持时间更长.3) 局地风场可以在湖中驱动形成一典型的水温水平分布、即浅水水温编高，深 水水温偏低的分布

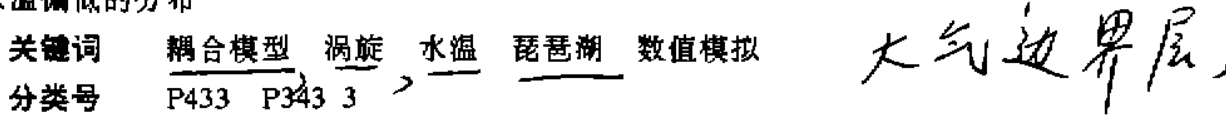

\section{The Influence of Atmospheric Boundary Layer on the Physical Processes of Lake Biwa, Japan}

\author{
Zhang Limin ${ }^{1,3}$ Michio Kumagai ${ }^{1}$ Pu Peimin ${ }^{2}$ \\ (1: Lakp Bizut Rereurch Institute, 1- I0 Uithidehama. Otsu, Shiga, 520 Japan; \\ 2: Nanjing Institufe of Gergraphy urd Lesunalugy. Chinese Acaderny of Sciences, Nanjing 210008, China; \\ 3: Environmental Protecton Bureas of Jiungeu Protince, Nanjing 210013, China)
}

\begin{abstract}
A numerical model coupling atmosphere with hybrodynamics is set up in this paper to study the gyres mechenism in Lake Biwa, Japan. Some results are obtained as follows: 1 \} There exists a postive wind vorticity field over the lake, and also a positive wind divergence field in daytime and ncgative one in night This special atmospheric boundary layer of Lake Biws catchment can generate a typical land-lake brecze, this local wind system can induce and maintain a weak but stable counter-clockwise gyre in north lake durng period of thermal strattication. 2) When considering inbomogeneous wind field, the gyres formed in the lake can sustain longer and be more stable than that only driven by homogcous wind over the lake 3) The local wind systen can produce a typical horizontal distribution of water tern. peraturc, i.c. water temperature higher in shallow water, lower in decp water.
\end{abstract}

Key Words Coupling model, gyres, water temperature, Lake Biwa, numersal simulation

- BITEX'93 影填目.

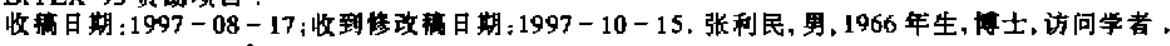


There are a lot of studies dealing with hydrodynamics and wind systems of lakes, numerical simulation of lake current systems ${ }^{[1.2]}$, numerical simulation on the land-lake/sea or mountain-valley breeze. Usually, the models in the atmospheric boundary layer and in lake water were simulated separately. In fact, the processes in the atmospheric boundary layer over lakes and the processes in the lake water are interacted strongly each other. Collected data show that most of all large lakes, marginal seas, estuaries and lagoons with the northern hemisphere are known to have a dominated counterclockwise pattern of circulation. The same are shown in Erhai Lake and Fuxian Lake, China; in Lake Biwa, Japan: and in Lake Baikal, Russia. There are many explanations, but it is still not clear enough. In many studies, a uniform wind field over lake surface is usually taken into account. But the daily meteorological data shows a complex pattern of wind system over large lakes. Lake Biwa is surrounded with mountains, it is found that there are two stable gyres and an unstable gyre in the surface layer during the season of thermal stratification. In order to study the formation mechanism of these gyre systems. a coupling three dimensional baroclinic model of Lake Biwa air-water system was developed.

Land-Lake breeze is one of the most typical wind system in Lake Biwa, Endoh ${ }^{[3]}$ measured the horizontal distribution of wind over Lake Biwa almost simultaneously by using three boats and testified that the inhomogeneous wind distribution to be one of the most important maintenance mechanisms of gyres in the Lake. In this paper, an atmospheric boundary layer model is setup and coupled with hydrodynamic model ${ }^{[4]}$ to study the influence of the inhomogeneous local wind field of land-lake on the gyres and water temperature in Lake Biwa. The dynamic and thermal difference between land and lake might play an important role to produce and maintain the long-term gyres in Lake Biwa.

\section{A Three Dimensional Model of Atmospheric Boundary Layer over Lake Biwa Catchment}

A topographic coordinate of $Z^{*}=Z_{\mathbf{H}} \frac{Z-Z_{G}}{Z_{\mathbf{H}}-Z_{G}}$ and the following equation system was used:

$$
\begin{aligned}
& \frac{\partial u}{\partial t}=-u \frac{\partial u}{\partial x}-v \frac{\partial u}{\partial y}-w \cdot \frac{\partial u}{\partial z^{*}}-\Theta \frac{\partial \pi^{\prime}}{\partial I}+g \frac{\theta^{\prime}}{\Theta} \frac{Z_{H}-Z^{*}}{Z_{\mathrm{H}}} \frac{\partial Z_{G}}{\partial I} \\
& +f\left(v-v_{s}\right)+\left(\frac{Z_{H}}{Z_{H}-Z_{G}}\right)^{2} \frac{\partial}{\partial z^{*}}\left(K_{z} \frac{\partial u}{\partial z^{*}}\right) \\
& \frac{\partial v}{\partial t}=-u \frac{\partial v}{\partial x}-v \frac{\partial v}{\partial y}-w^{*} \frac{\partial v}{\partial z^{*}}-\Theta \frac{\partial \pi^{*}}{\partial y}+g \frac{\theta^{\prime}}{\Theta} \frac{Z_{H^{*}}-Z^{*}}{Z_{H}} \frac{\partial Z_{G}}{\partial y} \\
& -f\left(u-u_{g}\right)+\left(\frac{Z_{H}}{Z_{H}-Z_{G}}\right)^{2} \frac{\partial}{\partial z^{4}}\left(K_{x} \frac{\partial u}{\partial z^{*}}\right) \\
& \frac{\partial \theta^{\prime}}{\partial t}=-u \frac{\partial \theta^{\prime}}{\partial x}-\nu \frac{\partial \theta^{\prime}}{\partial y}-w^{*} \frac{\partial \theta^{\prime}}{\partial z^{*}}+\left(\frac{Z_{H}}{Z_{\mathrm{H}}-Z_{\mathrm{G}}}\right)^{2} \frac{\partial}{\partial z^{*}}\left(K_{=} \frac{\partial \theta^{\prime}}{\partial z^{*}}\right)+F_{\mathrm{N}} \\
& \frac{\partial q}{\partial t}=-u \frac{\partial q}{\partial x}-v \frac{\partial q}{\partial y}-w^{*} \frac{\partial q}{\partial z^{*}}+\left(\frac{Z_{\mathrm{H}}}{Z_{\mathrm{H}}-Z_{G}}\right)^{2} \frac{\partial}{\partial z^{*}}\left(K_{*} \frac{\partial q}{\partial z^{*}}\right)
\end{aligned}
$$




$$
\begin{gathered}
\frac{\partial u}{\partial x}+\frac{\partial v}{\partial y}+\frac{\partial w^{*}}{\partial z^{*}}-\frac{1}{Z_{H}-Z_{i}}\left(u \frac{\partial Z_{G}}{\partial x}+v \frac{\partial Z_{\iota}}{\partial y}\right)=0 \\
\frac{\partial \pi^{\prime}}{\partial z^{*}}=\frac{Z_{\mathbf{H}}-Z_{G}}{Z_{H}} \frac{g \theta^{*}}{\theta^{2}}
\end{gathered}
$$

Where $u, v, w$ are wind components along the directions of $x, y, z$ separately; $w^{*}$, the vertical wind speed in transformed vertical coordinate $z^{*} ; u_{g}, v_{\mathrm{F}}$, the components of geostrophic wind: $f$, the Coriolis parameter; $Z_{H}$, the top height of the model; $Z_{C}$, the topographic height: $F_{N}$. the cooling tate of long wave radiation; $\theta, \Theta$ and $q$, the potential temperature, its reference value and specific humidity; $K$, is vertical coefficient of turbulent diffusion.

$$
\begin{gathered}
\theta^{\prime}=\theta-\Theta, \quad \pi^{\prime}=\pi-I I-\frac{f}{\Theta}\left(v_{\kappa} x-u_{\mathrm{g}} y\right), \quad \pi=C_{\mathrm{P}}\left(\frac{P}{P_{\infty}}\right)^{R j C_{\mathrm{T}}} \\
w^{\prime}=\frac{Z_{\mathrm{H}}}{Z_{\mathrm{H}}-Z_{\mathrm{G}}} w+\frac{Z^{*}-Z_{\mathrm{H}}}{Z_{\mathrm{H}}}\left(u \frac{\partial Z_{G}}{\partial x}+v \frac{\partial Z_{\mathrm{r}}}{\partial y}\right)
\end{gathered}
$$

Where $I, P_{\infty}$ are teference values of $\pi, P ; R, C_{\mathrm{P}}$ are constants.

\section{Three Dimensional Baroclinic Hydrodynamic Model in Lake Biwa}

The basic equation system for incompressible liquid is:

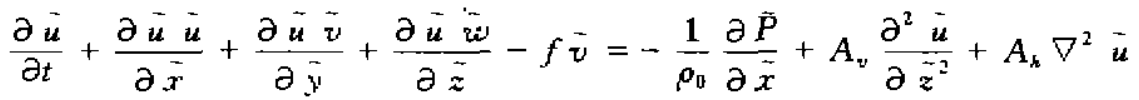

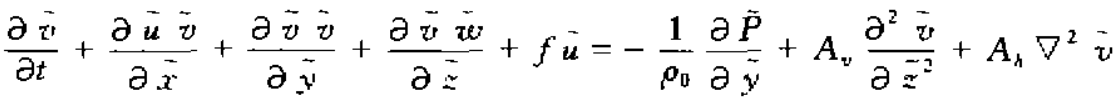

$$
\begin{aligned}
& \frac{\partial \tilde{T}}{\partial t}+\frac{\partial \tilde{u} \bar{T}}{\partial \dot{x}}+\frac{\partial \dot{v} \tilde{T}}{\partial \bar{y}}+\frac{\partial \tilde{u} \tilde{T}}{\partial z}=K_{\bar{x}} \frac{\partial^{2} \tilde{T}}{\partial \tilde{x}^{2}}+K_{\bar{y}} \frac{\partial^{2} \tilde{T}}{\partial \tilde{y}^{2}}+K_{z} \frac{\partial^{2} \tilde{T}}{\partial \bar{z}^{2}} \\
& \frac{\partial \vec{u}}{\partial \tilde{x}}+\frac{\partial \vec{v}}{\partial \tilde{y}}+\frac{\partial \tilde{u}}{\partial \vec{z}}=0 \\
& \hat{\rho}=\rho_{0}(1-\alpha \hat{T}) \\
& \frac{\partial \tilde{P}}{\partial \tilde{z}}=-\tilde{\rho} g
\end{aligned}
$$

Where axis $\dot{x}$ eastward, axis $y$ northward, axis $z$ downward; $\tilde{\rho}$ the water density; $\rho_{0}$, the mean water density; $\tilde{P}$, the pressure, $\tilde{T}, \alpha$, the water temperature and thermal expansion coefficient ; $\tilde{u}, \bar{v}, \bar{u}$, the components of the lake current: $A_{v}, A_{i z}, K_{5}, K_{3}$, the horizontal and vertical coeff $f_{-}$ cients of turbulent viscosity and of turbulent diffusion in directions of axes $\bar{x}, \bar{y}$, separately.

Introducing the buoyancy force $B=\frac{\left(\rho_{0}-\tilde{\rho}\right)}{\rho_{0}} g$, we have

$$
\begin{gathered}
\tilde{P}=\rho_{n} g \zeta-\rho_{0} \int B \mathrm{~d} z \\
\frac{\partial B}{\partial t}+\frac{\partial B \tilde{u}}{\partial \tilde{x}}+\frac{\partial B \tilde{v}}{\partial \tilde{y}}+\frac{\partial B \tilde{w}}{\partial \tilde{z}}=K_{\bar{z}} \frac{\partial^{2} B}{\partial \tilde{z}^{2}}+K_{k} \nabla^{2} B, \quad \frac{\partial B}{\partial \tilde{z}} \leq 0
\end{gathered}
$$

Where $\xi$ is the elevation of water surface. 


\section{Air-water Coupling Model}

Conditions on the air-water interface are as follows:

$$
\begin{aligned}
& K=\left.\rho \frac{\partial \tilde{v}}{\partial z}\right|_{z=0}=-\left.A_{v} \bar{\rho} \frac{\partial \tilde{v}}{\partial \tilde{z}}\right|_{z=0} \\
& Q=K \equiv \rho C_{c} \frac{\partial \tilde{T}}{\partial \tilde{z}} \vdots=0 \\
& Q=-Q_{\mathrm{s}}+Q_{\mathrm{b}}+Q_{\mathrm{e}}+Q_{\mathrm{c}} \\
& Q_{\mathrm{s}}=Q_{\mathrm{s}}(1-0.71 C)(1-r) \\
& Q_{\mathrm{b}}=S \sigma T^{4}\left(0.39-0.58 E_{\mathrm{h}}\right)\left(1-c C^{2}\right)+4 S \sigma T_{\mathrm{n}}{ }^{3}\left(T_{\mathrm{s}}-T_{\mathrm{a}}\right) \\
& Q_{\mathrm{r}}=\left.\rho_{\mathrm{a}} C_{\mathrm{P}} K_{z} \frac{\partial T_{\mathrm{z}}}{\partial z}\right|_{z=0}
\end{aligned}
$$$$
Q_{1}=L \rho E_{\mathrm{vap}}
$$

$$
E_{\text {vep }}=0.12 \times 10^{-5}+\left.\vec{V}\right|_{z=0}\left(E_{-}-E_{a}\right)
$$

Where $T_{\mathrm{a}}, \tau_{\mathrm{u}}, E_{\mathrm{a}}, E_{\mathrm{w}}$ are the air temperature,

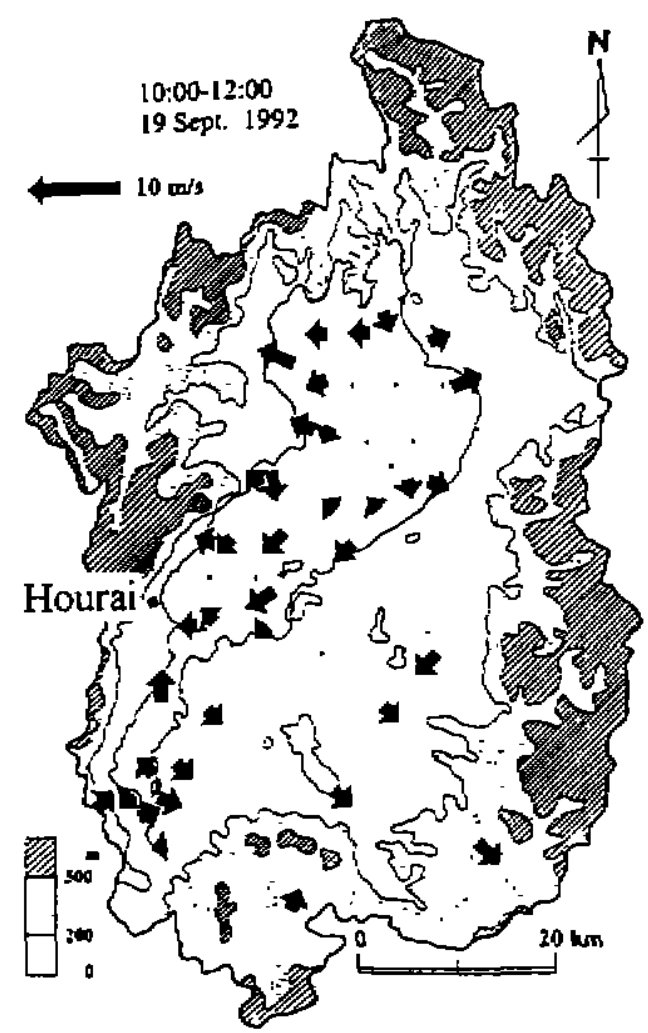

Fig. 1 An example of lakc brecze distribution obscrved between 10:00-12:00 on Scp.12. 1992 surface water temperature, air vapor pressure and saturated vapor pressure under $\tau_{5} ; C$, the cloudiness: $Q_{\mathrm{s}}, Q_{\mathrm{s}}$, the real solar radiation intensity and that of without cloud; $Q_{b}, Q_{c}, Q_{c}$, the effective radiation, turbulent sensible and latent heat fluxes; $r, s$, the albedo and long wave radiation emissivity of water surface; $s$, the Stefan-Bolzman constant; $L$, the latent heat of water; $E_{\text {vep }}, \mid \vec{V}^{\prime},=0$ are vapor pressure and air velocity on water surface.

\section{Results of Numerical Simulation}

4.1 The influence of land-lake breeze on the gyres in Lake Biwa

4.1.1 The observation and simulation results of land-lake breeze in lake Biwa Fig. 1 is an example of lake breeze observed in the morning of Sep. $19,1992^{22]}$, the wind is rather weak all over the lake carchment and a divergence point can be seen at the center of North Basin. The divergence is of the order of magnitude $10^{-4} \mathrm{~s}^{-1}$. It is also clearly expressed (Fig. 2) that there is obvious land lake breeze except some special weather conditions such as typhoon attack from Sep. 3 to Sep. 5 and 
from Sep. 7 to Sep.11. Almost allthe U-component of velocity is equal to or less than $0 \mathrm{~m} / \mathrm{s}$ at 0:00 in the night, it shows that the wind blows from west side to east, i.e. from land to lake in the night. Meanwhile, the $U$-component of wind velocity is more than $0 \mathrm{~m} / \mathrm{s}$ at $12: 00$, it shows the wind blows from lake to land in the daytime. The local wind system is typical land-lake breeze, which oscillate rliurnally.

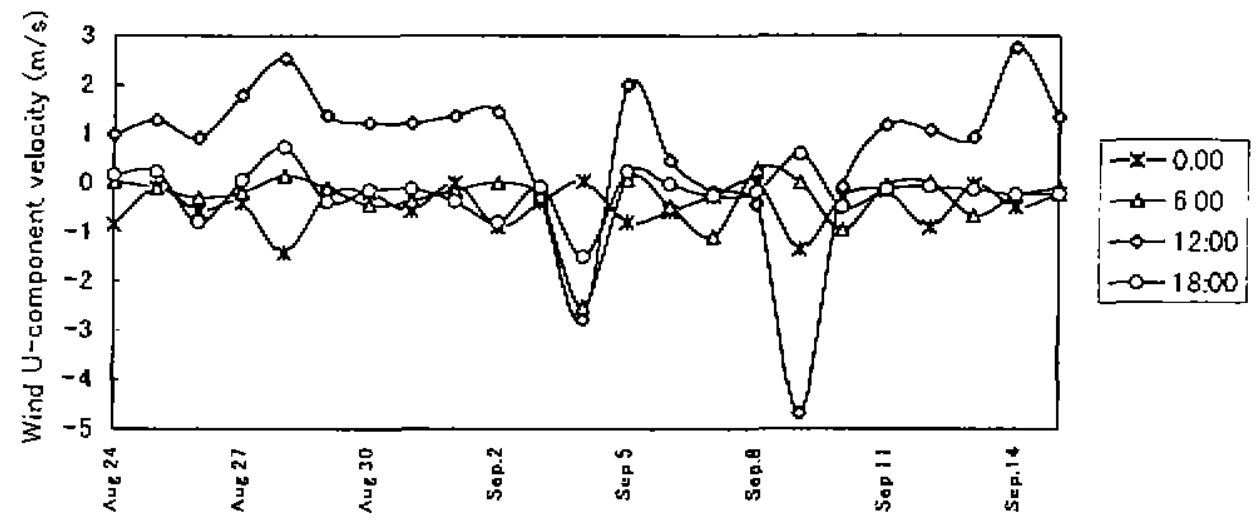

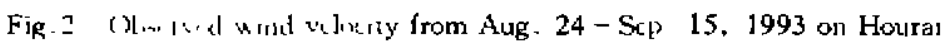

Fig. 3 describes the simulation results of $U$-component on Hourai and mean wind velocity over lake, it is found that there is typical lake-land breeze, wind blows from land to water in the night, and opposite in the daytime. The mean wind velocity (as shown in Fig. 3 ) is less than $2.5 \mathrm{~m} / \mathrm{s}$, which reaches maximum value in the afternoon.

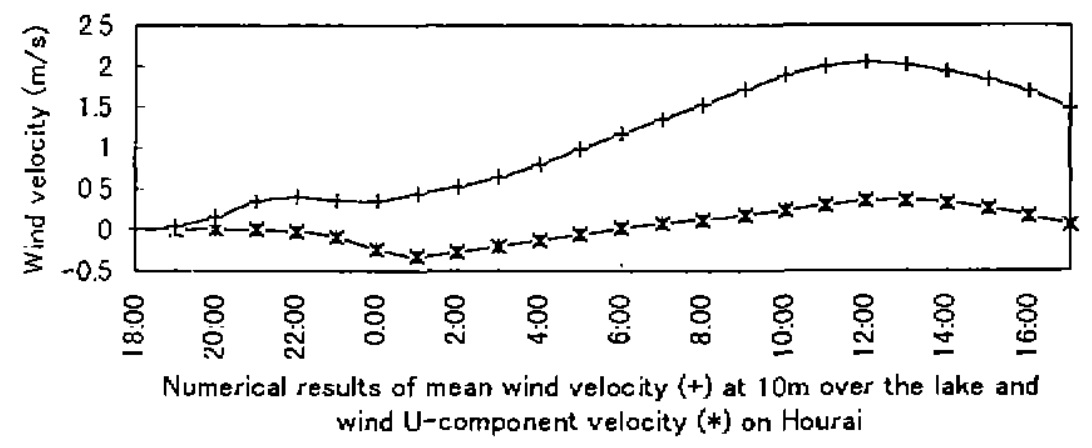

Fig.3 Numerical simulation of wind veloxity on Hourai from Aug. 24 to Alng.25

4.1.2 The influence of local wind system on the gyres in lake Fig. 4 shows that there exists a positive vorticty field, a positive divergence field in daytime and negative one in night within $24 \mathrm{~h}$ simulation.

Due to dynamic and thermal differences between land and lake, as well as mountains around Lake Biwa, there forms a special atmospheric boundary layer condition, which averagely produces 


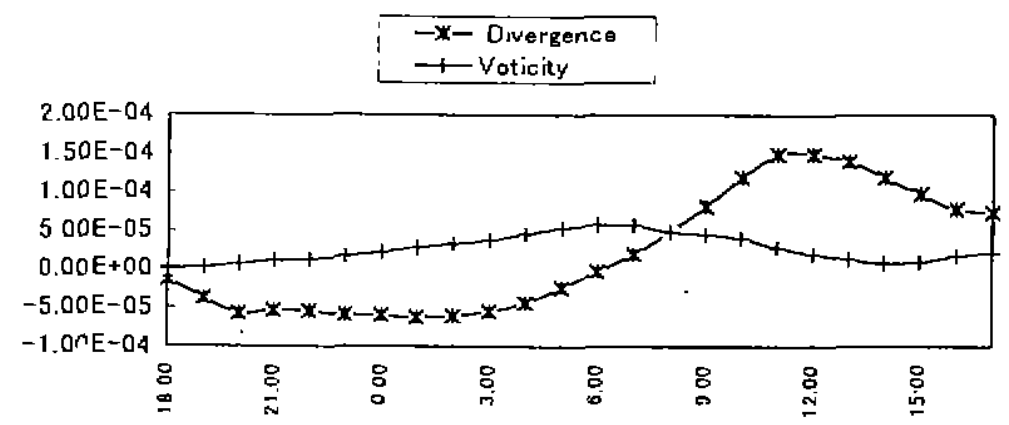

Fig 4 Mean vorticity $\left(\mathrm{s}^{-1}\right)$ and divergence $\left(\mathrm{s}^{-1}\right)$ over lake from Aug. 24 to Aug. 25

a positive vorticity and therefore might produce and sustain a weak gyre in Lake Biwa. Under this local wind system, the air-water coupling model runs for $10 \mathrm{~d}$, finally, a weak but stable current field is well expressed in Fig. 5a, it confirms the land-lake breeze is crucial to the gyres formation and maintenance. Meanwhile it shows (Fig. $5 \mathrm{~b}$ ) that under the hypothesis of no thermal stratification in the vertical direction of water. there is no gyre produced in lake after $10 \mathrm{~d}$ numerical sim. ulation.

It can be depicted that there exist gyres during thermal stratification, but no obvious gyres during no thermal stratification.

\subsection{The different characteristics of gyres produced under different conditions}

If geostrophic wind speed is assumed to be $10 \mathrm{~m} / \mathrm{s} \mathrm{SW}$, the gyres produced after $10 \mathrm{~d}$ simulation of air-water coupling model are obtained as follows.

There obviously sustains a stable counter-clockwise and a clockwise gyres (Fig. $5 \mathrm{c}$ ) in the north Lake Biwa. Meanwhile, it is assumed that driven by spatially uniform wind of $5 \mathrm{~m} / \mathrm{s}$ at $10 \mathrm{~m}$ height over the lake, which on the average has the same order of magnitude of wind velocity at the $10 \mathrm{~m}$ level produced by geostrophic wind of $10 \mathrm{~m} / \mathrm{s}$, the simulation results is depicted as Fig. 5 d.

Compared with Fig. 5c and Fig. 5d, the gyre driven by inhomogeous wind is more obvious. stable than that by homogeneous one. It can say that the special terrain around the lake, the dynamic and thermal differences between lake and land play important roles in the formation and sustainence of gyres, under the condition of fairly strong wind field.

\subsection{The influence of local wind system on the distribution of water temperature}

If geostrophic wind equals to $0 \mathrm{~m} / \mathrm{s}$, and also the horizontal distribution of water temperature is assumed to be spatially uniform initially. The objective of this test is to examine the wind effect on horizontal distribution of water temperature.

It is evident (Fig . 6) that despite the initial hypothesis of water temperature is spatially uniform water temperature, but finally, an adaptive temperature field can be generated by the local wind system, i.e. water temperature a little bit higher in shallow water, lower in deep water. 

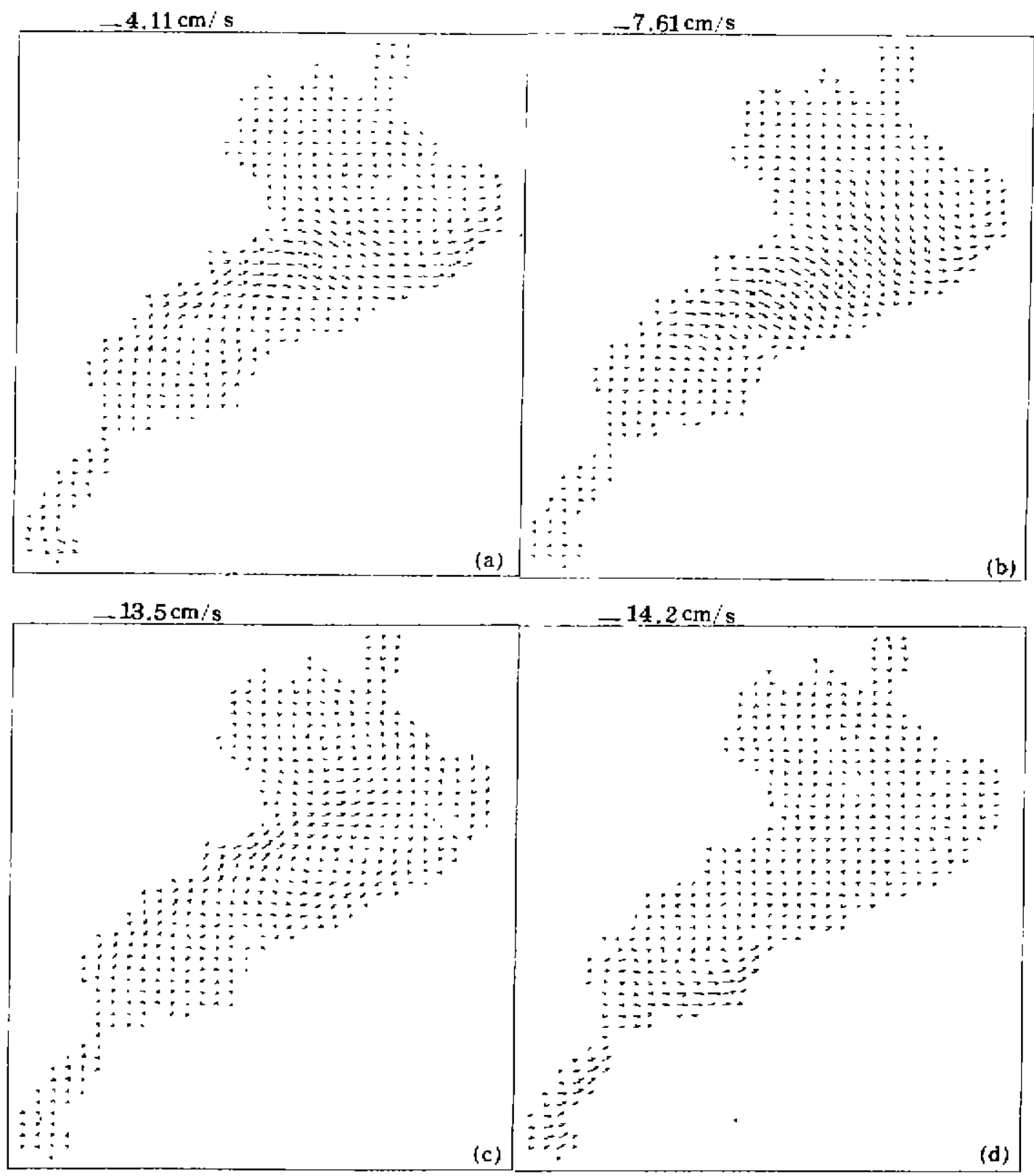

Fig. 5 The currents when numerical simulation over $10 \mathrm{~d}$

\section{Some preliminary results}

(1) There exist a positive wind vorticity field over the Lake, and also a positive wind divergence field in daytime and negative one in the night. This special atmospheric boundary layer of Lake Biwa catchment can generate a typical land-lake breeze, this local wind system can induce and maintain a weak but stable counter-clockwise gyre in north lake during period of thermal 


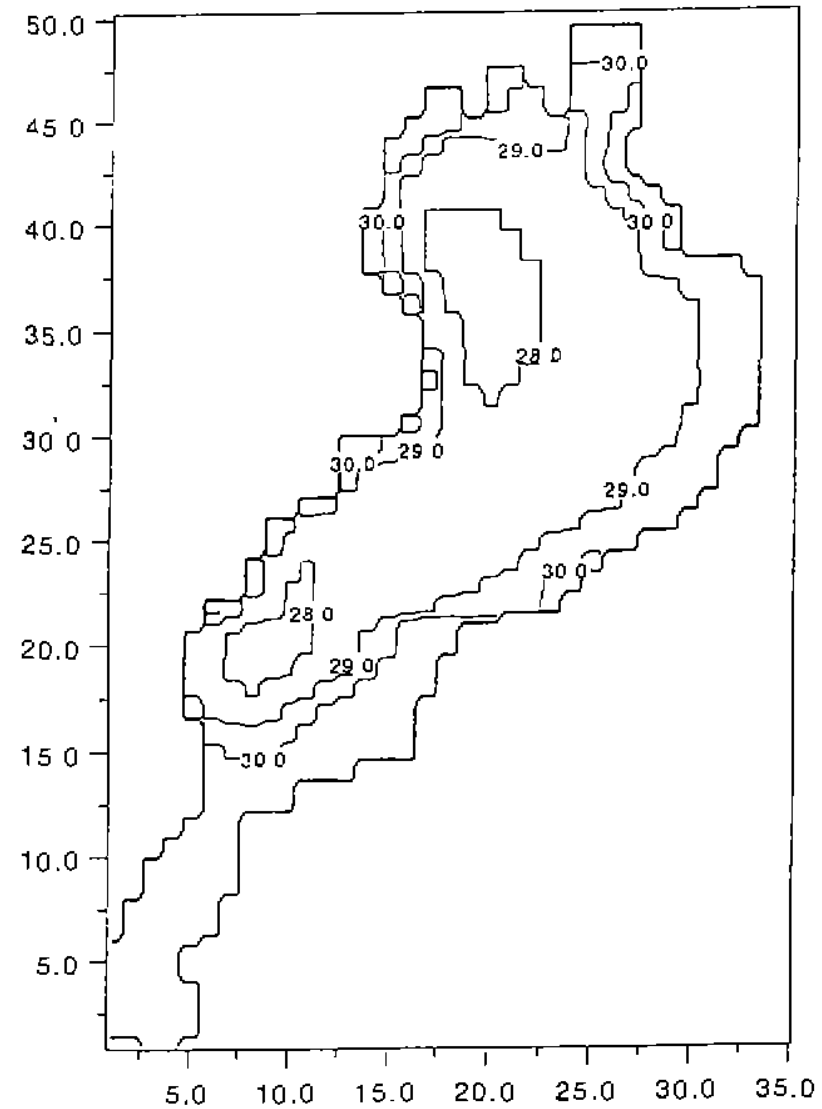

Fig 6 Under the initial hypothess of uniform water temperature distribution, the result of water temperature distribution after $10 \mathrm{~d}$ simulation

stratification.

(2) When considering the inhomogeneous wind field, the gyres formed in the lake can sustain longer and be more stable than that only driven by homogeneous wind over the lake.

(3) The local wind system can produce a typical horizontal distribution of water temperature, i.e. water temperature higher in shallow water, lower in deep water.

\section{References}

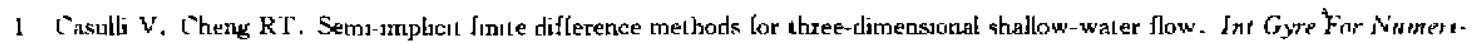
. ul Methixls en Fluseds, 1992.15:029-649

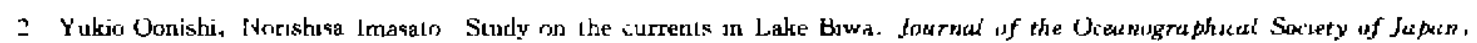
$1975,31: 53-611$

3 Endoh S. Mwa Watanabe, Hirnks Nagata, et at. Wund Gelis over Lake Buwa and their effect ron water circulaton tapun Jour nul of Lem rulogy. 1995, 56(4) : $269-278$

4 Zhang Lımun. Pu Permun. A couphing three dumensional taroclinic model of Lake biwa air-water systern. The Journat of Clksnese Georruphy. 1996, 6(3):76-83 